\title{
Kendali Optimal Pada Model Persediaan Barang Yang Mengalami Weibull Deterioration Pada Waktu Berhingga
}

\author{
Nilwan Andiraja ${ }^{1}$, Nidia Mindiyarti ${ }^{2}$ \\ ${ }^{1,2}$ Program Studi Matematika, Fakultas Sains dan Teknologi, UIN Sultan Syarif Kasim Riau \\ Jl. HR. Soebrantas No. 155 Simpang Baru, Panam, Pekanbaru, 28293 \\ Email: nilwanandiraja@uin-suska.ac.id,nidiamindiyarti@gmail.com
}

\begin{abstract}
ABSTRAK
Kerusakan barang merupakan hal yang umum terjadi pada sistem persediaan.Barang-barang yang mudah rusak dapat mengakibatkan kerugian bagi perusahaan.Oleh karena itu, perlu adanya pengendalian terhadap persediaan yang dilakukan dengan penerapan teori kendali.Penelitian ini membahas penerapan teori kendali yang bertujuan untuk mendapatkan persamaan tingkat persediaan barang yang optimal dan mendapatkan kestabilan model matematika pada model kerusakan barang yang mengalami Weibull Deterioration pada waktu berhingga. Model persediaan barang yang digunakan adalah persamaan diferensial dinamik dimana fungsi permintaan diubah menjadi fungsi kuadrat dan fungsi kerusakan diubah menjadi Weibull Deterioration. Persamaan yang ada digunakan untuk mendapatkan fungsi Hamilton, fungsi Lagrange, solusi dari persamaan yang diselesaikan dengan dua kasus dan analisa kestabilan.Hasil dari penelitian menunjukkan bahwa persamaan memenuhi semua syarat-syarat yang diperlukan untuk kondisi optimal.Selain itu, berdasarkan contoh yang telah diberikan didapat bahwa kurva menurun pada waktu yang telah ditentukan.Artinya, persamaan stabil asimtotik pada waktu yang telah ditentukan.
\end{abstract}

Kata kunci:Kendali, Kestabilan, Optimal, Penurunan Barang, Persediaan.

\begin{abstract}
The Damage of goods is a common issue in the inventory system. Perishable goods can cause harm to the company. Therefore, the inventory control is needed by applying control theory. This research discusses the application of control theory that aims to obtain an optimal equation of inventory levels and obtain stability of mathematical models on models of damage to goods with Weibull Deterioration at finite time. The inventory model used is a dynamic differential equation where the demand function is changed to a quadratic function and the damage function is changed to Weibull Deterioration. The equation is used to get the Hamilton function, the Lagrange function, the solution of the equation solved by two cases and the stability analysis. The results of the study show that the equation fulfills all the conditions needed for optimal conditions. In addition, based on the example given, it is found that the curve decreases at a predetermined time. That means, the asymptotic stable equation at a predetermined time.
\end{abstract}

Keywords: Control, Decline in Good, Inventory, Optimal, Stability.

\section{Pendahuluan}

Persediaan berkaitan dengan penyimpanan bahan baku, bahan setengah jadi, dan barang jadi untuk memastikan lancarnya produksi atau kegiatan bisnis bagi suatu perusahaan atau industri.Teori kendali merupakan teori yang dapat digunakan dalam menyelesaikan persoalan tingkat persediaan. Salah satu penelitian yang membahas tingkat persediaan dapat dilihat pada [13], yang menyebutkan, tingkat persediaan adalah 
pengendalian yang menentukan tingkat persediaan yang harus dijual, kapan persediaan harus diisi, dan berapa besar pesanan yang harus dilakukan.

Persediaan dapat menjadi beban bagi keuangan perusahaan karena mengakibatkan dana menganggur lebih besar, resiko kerusakan barang lebih besar, dan biaya penyimpanan lebih besar. Kerusakan barang merupakan hal yang umum terjadi pada sistem persediaan. Barang-barang seperti susu, obat-obatan, komponen elektronik, telur, bensin dan lainnya dikatakan barang yang kualitasnya memburuk (kualitasnya menurun) selama periode penyimpanan normal yang mengakibatkan kerugian. Oleh karena itu, perlu adanya pengendalian terhadap persediaan sehingga persediaan dapat optimal yang dapat dilakukan dengan penerapan teori kendali.Mengingat pentingnya pengendalian terhadap persediaan ini, maka penulis tertarik untuk melakukan penelitian mengenai kendali optimal pada masalah persediaan barang yang menggunakan fungsi kuadrat sebagai fungsi permintaan [2,4] dan Weibull Deterioration pada fungsi kerusakan [11].

\section{Metode dan Bahan Penelitian}

\section{Model Persediaan Barang}

\section{a. Kendali Optimal pada Masalah Persediaan Barang}

Pembentukan model ini didasarkan pada sistem persediaan dimana ditinjau persediaan saat terjadi peningkatan dan penurunan barang. Di asumsikan bahwa fase pertama dari $t_{0}$ hingga $t_{1}$ untuk tingkat persedian yang meningkat, kemudian fase kedua yaitu $t_{1}$ hingga $t_{2}$ untuk tingkat persediaan yang menurun. Berikut ini digambarkan model persediaan yang mengalami fase perubahan inventori.

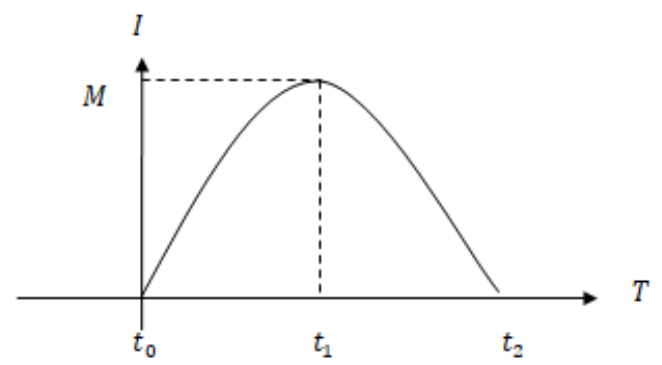

Gambar 1. Model Persediaan dengan Perubahan Fase (Affandi, 2015)

Pada Gambar 1di atas, membahas dua kasus, yaitu kasus model penurunan barang dan model kenaikan barang. Kedua kasus tersebut dapat didefinisikan dalam persamaan differensial dinamik, yaitu:

$$
\dot{I}=\left\{\begin{array}{lr}
P(t)+v(t) I(t), & t \in\left[0, t_{1}\right] \\
P(t)-D(t)+v(t) I(t), & t \in\left[t_{1}, t_{2}\right]
\end{array} .\right.
$$

Dalam penelitian ini, hanyaakan dibahas persoalan untuk kasus penurunan barang.Kasus penurunan barang dapat didefinisikan denganpersamaan differensial dinamik [1], yaitu:

$$
\dot{I}=P(t)-D(t)+v(t) I(t) \quad t \in\left[t_{1}, t_{2}\right]
$$

dengan $v(t)=m(t)-\theta(t), P(t) \geq 0$. Kemudian, untuk menjamin tingkat persediaan menurun darit $t_{1}$ hinggat $t_{2}$, lebih lanjut Persamaan (1) memenuhi:

$$
P(t)-D(t)+v(t) I(t)>0 \quad t \in\left[t_{1}, t_{2}\right]
$$

dengan

$I(t) \quad$ : Tingkat fungsi persediaan.

$P(t) \quad$ : Tingkat fungsiproduksi.

$D(t) \quad$ : Fungsi permintaan.

$I_{0} \quad$ : Tingkat nilai awal persediaan.

$m(t) \quad$ : Rata-rata fungsi kenaikan. 
$\theta(t) \quad$ : Rata-rata fungsi kemerosotan.

$\mathrm{v}(\mathrm{t}) \quad$ : Selisih dan rata-rata fungsi kenaikan dan penurunan

Dari Persamaan (2) di atas, akan dicari fungsi tujuan. Fungsi tujuan dari model persediaan barang yang mengalami penurunan adalah sebagai berikut:

dengan

$$
J=\frac{1}{2} \int_{0}^{t}\left\{h[I(t)-\hat{I}]^{2}+K[P(t)-\hat{P}]^{2}\right\} d t
$$

$\hat{P}$ : Tingkat produksi tujuan.

$\hat{I}$ : Tingkat persediaan tujuan.

$h$ : Koefisien biaya penyimpanan.

$K$ : Koefisien biaya produksi.

Selanjutnya, untuk mencari tingkat produksi yang optimal, persamaan diferensial dinamik yang ada diubah ke bentuk persamaan Hamilton [1].Selanjutnya, didefinisikan persamaan Hamilton sebagai berikut:

dengan

$$
H=\frac{1}{2}\left[h(I-\hat{I})^{2}+K(P-\hat{P})^{2}\right]+\lambda g,
$$

$$
g=P(t)-D(t)+v(t) I(t) \quad t \in\left[t_{1}, t_{2}\right]
$$

danfungsi Lagrange adalah sebagai berikut:

$$
L=\frac{1}{2}\left[h(I-\hat{I})^{2}+K(P-\hat{P})^{2}\right]+(\lambda-\mu) g, \quad t \in\left[t_{1}, t_{2}\right]
$$

Menurut [10] syarat yangdiperlukan untuk kondisi optimalyaitu,

$$
\begin{aligned}
& H p=0 \\
& L_{I}=-\dot{\lambda} \\
& L_{p}=0 \\
& \mu \geq 0, \mu g \geq 0
\end{aligned}
$$

\section{b. Model Persediaan dengan Fungsi Kuadrat}

Hasil penelitian [2] menyebutkan, ketika kerusakan barang dan perubahan tingkat permintaan dengan tingkat permintaan diasumsikan dengan bentuk fungsi kuadrat, kerusakan yang terjadi menjadi sangat kecil dan konstan. Berdasarkan [3], fungsi kuadrat yang digunakan dalam asumsi tingkat permintaan $(D(t))$ pada model persediaan pada penelitian ini yaitu,

$$
D(t)=a+b t+c t^{2}
$$

Dengan $a, b, c$ merupakan konstanta dengan waktu $t$.

\section{c. Weibull Deterioration}

Pada persediaan barang, tingkat penurunan persediaan barang dapat diakibatkan oleh rusaknya atau cacatnya barang-barang persediaan. Rusak atau cacatnya barangbarang persediaan dapat diakibatkan oleh hal-hal yang tidak dapat diprediksi. Menurut [14], di dalam statistika kerusakan yang didapat dari sebab yang tidak dapat diprediksi, diketahui dapat digambarkan dengan distribusi Weibull. Oleh karena itu, menurut [11] untuk penurunan persediaan yang diakibatkan oleh hal-hal yang tidak diprediksi pada artikel ini dinyatakan sebagai Weibull deterioration.

\section{d. Model Persediaan dengan Distribusi Weibull}

Tingkat penurunan pada model persediaan dapat mengikuti distribusi Weibull dengan dua parameter seperti dijelaskan dalam penelitian Sharma [11]. Distribusi Weibull dua parameter didefinisikan sebagai berikut:

$$
\theta(t)=\alpha \beta t^{\beta-1} e^{-\beta t^{c}}
$$


Dimana $0<\alpha<1$ adalah skala parameter dan $\beta>0$ adalah bentuk parameter.

Berdasarkan distribusi Weibull pada Persamaan (12), tingkat persediaan dengan distribusi Weibull didefinisikan sebagai berikut:

$$
\frac{d I(t)}{d t}+\alpha \beta t^{\beta-1} e^{-\beta t^{c}} I(t)=P(t)-\left(a+b t+c t^{2}\right) \quad 0 \leq t \leq t_{1}
$$

Penulisan artikel ini membahas penyelesaian model persediaan barang yang mengalami penurunan barang. Dalam penelitian ini akan dilakukan tahapan-tahapan sebagai berikut:

1. Diketahui persamaan diferensial dinamik untuk penurunan barang sebagai berikut:

$$
\dot{I}=P(t)-\left(a+b t+c t^{2}\right)+\alpha \beta t^{\beta-1} e^{-\beta t^{c}} I(t) \quad t \in\left[t_{1}, t_{2}\right]
$$

Kemudian berdasarkan Persamaan (3) diketahui fungsi tujuan untuk kasuspenurunan barang pada waktu berhingga adalah sebagai berikut:

$J=\frac{1}{2} \int_{0}^{t}\left\{h[I(t)-\hat{I}]^{2}+K[P(t)-\hat{P}]^{2}\right\} d t$

2. Dari persamaan diferensial dinamik untuk kasus penurunan barang dan fungsi tujuan untuk kasus penurunan barang pada waktu berhingga yang telah diketahui, diperoleh persamaan Hamilton dan fungsi Lagrange.

3. Setelah diperoleh persamaan Hamilton dan fungsi Lagrange, dicari syarat-syarat kondisi optimal, yaitu ditentukan $H_{P}=0, L_{I}=-\dot{\lambda}(19)$ dan $L_{p}=0$.

4. Dari pengerjaan syarat-syarat kondisi optimal, diperoleh nilai tingkat produksi $P(t)$. Selanjutnya, nilai $P(t)$ yang telah diperoleh disubstitusi ke persamaan diferensial dinamik untuk kasus penurunan barang $(I)$ pada langkah nomor 1 .

5. Selanjutnya, untuk memperoleh fungsi persediaan barang yang optimal, persamaan diferensial dinamik untuk kasus penurunan barang yang telah diperoleh $(\dot{I})$ diturunkan terhadap kondisi waktu yang ditetapkan $\left(\frac{d}{d t}(\dot{I})\right)$.

6. Untuk menentukan persamaan tingkat persediaan yang optimal $(I(t))$, persamaan tingkat fungsi produksi yang optimal $(D(t))$, dan fungsi penurunan barang $\alpha \beta t^{\beta-1} e^{-\beta t^{c}}(\mathrm{t})$ harus diperoleh solusi dari persamaan yang telah didapatkan pada langkah nomor 5 dengan mengamati dua kasus dalam bentuk solusi eksplisit, yaitu kasus dimana fungsi $\alpha \beta t^{\beta-1} e^{-\beta t^{c}}(\mathrm{t})$ adalah fungsi konstanta dan fungsi $\frac{h}{k}+\left(\frac{d}{d t}\left(\alpha \beta t^{\beta-1} e^{-\beta t^{c}}(\mathrm{t})\right)+\right.$ $\alpha \beta t^{\beta-1} e^{-\beta t^{c}}(\mathrm{t})$ adalah konstanta.

7. Dari langkah nomor 6, diperoleh solusi konstanta, yaitu untuk nilai $C_{1}$ dan $C_{2}$ dan juga nilai $Q_{t}$ yang digunakan untuk menentukan kestabilan, dimana persamaan akan stabil asimtotik untuk waktu t jika menuju kesatu nilai.

\section{Hasil dan Pembahasan}

\section{Kendali Optimal pada Masalah Persediaan Barang}

Penelitian ini membahas mengenai teori kendali dengan kasus penurunan barang. Sesuai Persamaan (5), persamaan diferensial dinamik untuk kasus persediaan barang yang mengalami penurunan barang adalah:

$$
\dot{I}=P(t)-D(t)+v(t) I(t), \quad t \in\left[t_{1}, t_{2}\right]
$$

Dalam penelitian ini, fungsi permintaan $D(t)$ diubah menjadi fungsi kuadrat $\left(a+b t+c t^{2}\right)$ dan fungsi kerusakanv $(t) I(t)$ diubah menjadi distribusi Weibull $\alpha \beta t^{\beta-1} e^{-\beta t^{c}} I(t)$. Sehingga persamaan diferensial dinamik untuk kasus persediaan barang yang mengalami penurunan dengan Weibull Deterioration berubah menjadi:

$$
\dot{I}=P(t)-\left(a+b t+c t^{2}\right)+\alpha \beta t^{\beta-1} e^{-\beta t^{c}} I(t), t \in\left[t_{1}, t_{2}\right]
$$


Selanjutnya, untuk penyederhanaan tulisan dinotasikan $I(t)=I$ dan $P(t)=P$ dan Weibull Deterioration $\left(\alpha \beta t^{\beta-1} e^{-\beta t^{c}}\right)$ dinotasikan dengan $W_{b}$. Dari Persamaan (3) diketahui fungsi tujuan dari model persediaan barang yang mengalami penurunan adalah sebagai berikut:

$$
J=\frac{1}{2} \int_{0}^{t}\left\{h[I-\hat{I}]^{2}+K[P-\hat{P}]^{2}\right\} d t
$$

Kemudian, untuk mencari tingkat produksi yang optimal dilakukan dengan membentuk persamaan Hamilton sesuai Persamaan (4).

$$
H=\frac{1}{2}\left[h(I-\hat{I})^{2}+K(P-\hat{P})^{2}\right]+\lambda P-\lambda\left(a+b t+c t^{2}\right)+\lambda W_{b} I
$$

Dan fungsi Lagrangenya adalah:

$$
\begin{aligned}
L= & \frac{1}{2} h(I-\hat{I})^{2}+\frac{1}{2} K(P-\hat{P})^{2}+P(\lambda-\mu)+I\left(\lambda W_{b}-\mu W_{b}\right) \\
& +(\mu-\lambda)\left(a+b t+c t^{2}\right)
\end{aligned}
$$

Selanjutnya, dari $H_{p}=0$ diperoleh tingkat produksi sebagai berikut:

$$
P=\hat{P}-\frac{\lambda}{K}
$$

Syarat selanjutnya yang harus dipenuhi untuk kondisi optimal sesuai Persamaan (8) adalah $L_{I}=-\dot{\lambda}$. Diperoleh:

$$
\dot{\lambda}=-h(I-\hat{I})+(\mu-\lambda) W_{b}
$$

Dan $L_{p}=0$ yaitu:

$$
\begin{aligned}
L_{p} & =\frac{K}{2} 2(P-\hat{P})+(\lambda-\mu) \\
(\mu-\lambda) & =K(P-\hat{P})
\end{aligned}
$$

Selanjutnya, substitusi Persamaan (18) ke persamaan diferensial dinamik pada Persamaan (14) sehingga menjadi:

$$
\dot{I}=\left(\hat{P}-\frac{\lambda}{K}\right)-\left(a+b t+c t^{2}\right)+W_{b} I
$$

Selanjutnya Persamaan (21) dideferensialkan sehingga diperoleh:

$$
\ddot{I}=-\frac{\dot{\lambda}}{K}-b-2 c t+\left(\frac{d}{d t}\left(W_{b}\right)\right) I+W_{b} \dot{I}
$$

Substitusi Persamaan (19) dan Persamaan (21) ke Persamaan (22) sehingga diperoleh:

$$
\begin{aligned}
\ddot{I}= & -\frac{-h(I-\hat{I})+(\mu-\lambda) W_{b}}{K}-b-2 c t+\left(\frac{d}{d t}\left(W_{b}\right)\right) I \\
& +W_{b}\left(\left(\hat{P}-\frac{\lambda}{K}\right)-\left(a+b t+c t^{2}\right)+W_{b} I\right)
\end{aligned}
$$

Dengan mensubstitusikan Persamaan (20) dan Persamaan (18) diperoleh:

$$
\ddot{I}-\left(\frac{h}{K}+\frac{d}{d t}\left(W_{b}\right)+\left(W_{b}\right)^{2}\right) I=-\frac{h \hat{I}}{K}+W_{b} \hat{P}-W_{b}\left(a+b t+c t^{2}\right)-(b+2 c t)
$$




$$
\ddot{I}-\left(\frac{h}{K}+\frac{d}{d t}\left(W_{b}\right)+\left(W_{b}\right)^{2}\right) I=a_{1}
$$

Selanjutnya, untuk menentukan persamaan tingkat persediaan yang optimal $(I)$ persamaan tingkat fungsi produksi yang optimal $(P)$ dan fungsi penurunan barang $W_{b}$ harus diperoleh solusi dari Persamaan (24). Solusi Persamaan (24) akan diamati dua kasus dalam bentuk solusi eksplisit. Dua kasus yang akan diselesaikan dalam bentuk solusi eksplisit dijelaskan dalam pembahasan selanjutnya.

\section{a. $\quad$ Fungsi $W_{b}$ adalah Konstan}

Pada saat fungsi $\boldsymbol{W}_{\boldsymbol{b}}$ adalah konstan, maka persamaan diferensial dari Persamaan (24) akan diperoleh sebagai berikut:

$$
\ddot{I}-\left(\frac{h}{K}+\left(W_{b}\right)^{2}\right) I=-\frac{h \hat{I}}{K}+W_{b} \hat{P}-W_{b}\left(a+b t+c t^{2}\right)-(b+2 c t)
$$

Akar-akar karakteristik dari Persamaan (25) memiliki solusi sebagai berikut:

$$
r_{1}=\sqrt{\frac{h}{K}+\left(W_{b}\right)^{2}}=r \operatorname{dan} r_{2}=-\sqrt{\frac{h}{K}+\left(W_{b}\right)^{2}}=-r
$$

Sehingga solusi dari Persamaan (25) akan diberikan dalam bentuk:

$$
I(t)=c_{1} e^{r t}+c_{2} e^{-r t}+Q(t)
$$

Dengan $Q(t)=\frac{\frac{h}{\hat{I}} \hat{+} W_{b}\left(-\hat{P}+a+b+c t^{2}\right)+(b+2 c t)}{\left(\frac{h}{K}+W_{b}^{2}\right)}$

b. $\quad$ Fungsi $\frac{h}{K}+\left(\frac{d}{d t} W_{b}\right)+\left(W_{b}\right)^{2}$ adalah Konstan

Apabila fungsi $\frac{\boldsymbol{h}}{\boldsymbol{K}}+\left(\frac{\boldsymbol{d}}{\boldsymbol{d} t} \boldsymbol{W}_{\boldsymbol{b}}\right)+\left(\boldsymbol{W}_{\boldsymbol{b}}\right)^{\mathbf{2}}$ dalam bentuk konstan, persamaannya dapat ditulis sebagai berikut:

$$
\frac{h}{K}+\left(\frac{d}{d t} W_{b}\right)+\left(W_{b}\right)^{2}=k_{1}^{2}
$$

Sehingga persamaan diferensial dari Persamaan (24) akan berubah menjadi:

$\ddot{I}-\left(k_{1}^{2}\right) I=-\frac{h \hat{I}}{K}+W_{b} \hat{P}-W_{b}\left(a+b t+c t^{2}\right)-(b+2 c t) t \in\left[t_{1}, t_{2}\right]$

Selanjutnya, untuk menyelesaikan Persamaan (28), terlebih dahulu dihitung faktor penurunan Weibull $\left(W_{b}\right)$, sehingga diperoleh:

$$
W_{b}(t)=\frac{a\left(e^{2 a t}+1\right)}{\left(e^{2 a t}-1\right)}
$$

Kemudian, Persamaan (29) disubstitusikan ke Persamaan (28) sehingga diperoleh solusi untuk Persamaan (28) sebagai berikut:

$\ddot{I}-\left(k_{1}^{2}\right) I=-\frac{h \hat{I}}{K}-\frac{a\left(e^{2 a t}+1\right)}{\left(e^{2 a t}-1\right)}\left(-\hat{P}-a+b+c t^{2}\right)-(b+2 c t)$

Dengan $r_{1}=k_{1}, r_{2}=k_{2}$, dan $Q(t)=W_{b_{1}} e^{k_{1} t}+W_{b_{2}} e^{-k_{1} t}+\frac{h}{K k_{1}^{2}} \hat{I}$

\section{Simulasi Tingkat Persediaan}

Berdasarkan penelitian dari Hazmuzalipa (2018) diketahui sebuah perusahaan $X$ memproduksi sebuah barang dengan rata-rata fungsi kenaikan $(m)$ sebesar 0.01, tingkat persediaan tujuan $(\hat{I})$ sebesar 40 , tingkat produksi tujuan $(\hat{P})$ sebesar 22, tingkat fungsi 
persediaan $\left(t_{2}\right)$ sebesar 10, tingkat persediaan maksimum $(M)$ sebesar 35, koefisien biaya penyimpanan $(h)$ sebesar 1.8, fungsi permintaan $\left(a+b t+c t^{2}\right)$ dengan parameter $a=4$, $b=10$, koefisien biaya produksi $(K)$ sebesar 64 , dengan parameter untuk persamaan Weibull adalah $\alpha=2, \beta=1$, danc=0. Tentukan nilai optimal tingkat persediaan $(I(t))$ dan analisis kestabilannya pada saat $t \in[0,15], t \in[0,18]$ dan $t \in[0,100]$.

\section{Penyelesaian:}

Sebelum menentukan nilai optimal untuk tingkat persediaan, terlebih dahulu dihitung nilai $r$ dan $Q(t)$. Berdasarkan nilai parameter yang diberikan pada simulasi di atas diperoleh $r=-2.0070189$ dan $Q(t)=0.00027283165+60 t$

Selanjutnya, pada saat $t=10$, nilai $Q(t)$ menjadi $Q(t)=600.00027283$

Kemudian, dari nilai-nilai di atas diperoleh

$c_{1}=2.258891103 \times 10^{-17}, c_{2}=0.0556005903 \mathrm{dan}$

$I(t)=2.25889110310^{-17} e^{2.0070189 t}+0.0556005903 e^{-2.0070189 t}$

Solusi persamaan $I(t)$ untuk $t \rightarrow 15$ hasilnya dapat dilihat pada grafik berikut:

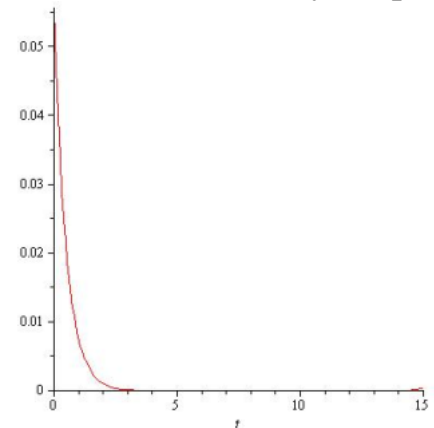

Gambar 2. Grafik $I(t)$ untuk $t \rightarrow 15$

Berdasarkan Gambar 2, diperoleh bahwa tingkat persediaan $I(t)$ mengalami penurunan pada waktu $t \rightarrow 15$. Persediaan barang terus mengalami penurunan yang dimulai sejak $t=2$ sampai $t=15$. Hal ini disebabkan karena meskipun ada proses produksi barang, terdapat permintaan dan kerusakan yang terjadi pada barang. Sehingga dapat diambil kesimpulan bahwa tingkat persediaan $I(t)$ mencapai stabil asimtotik pada saat $t \rightarrow 15$ dimana grafik menuju 0 . Selanjutnya, akan dilihat solusi persamaan $I(t)$ untuk $t \rightarrow 18$ sebagai berikut:

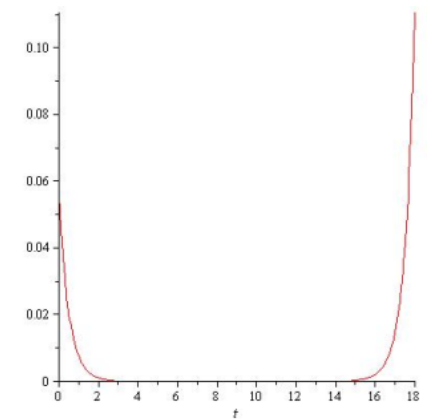

Gambar 3. Grafik $I(t)$ untuk $t \rightarrow 18$

Berdasarkan Gambar 3, diperoleh bahwa tingkat persediaan $I(t)$ mengalami kenaikan pada waktu $t \rightarrow 18$. Persediaan barang terus mengalami penurunan yang dimulai sejak $t=2$ sampai $t=15$ namun mengalami kenaikan ketika $t=16$ menuju tak hingga.Hal ini disebabkan karena meskipun terdapat permintaan dan kerusakan yang terjadi pada barang, produksi tetap dilakukan sehingga menyebabkan tingkat persediaan barang mengalami 
kenaikan. Sehingga dapat diambil kesimpulan bahwa tingkat persediaan $I(t)$ menjadi tidak stabil pada saat $t \rightarrow 18$ dimana grafik menuju 0 sampai $t=15$ namun naik terus menuju $\infty$ pada saat $t \rightarrow 18$ Selanjutnya, akan dilihat solusi persamaan $I(t)$ untuk $t \rightarrow 100$ sebagai berikut:

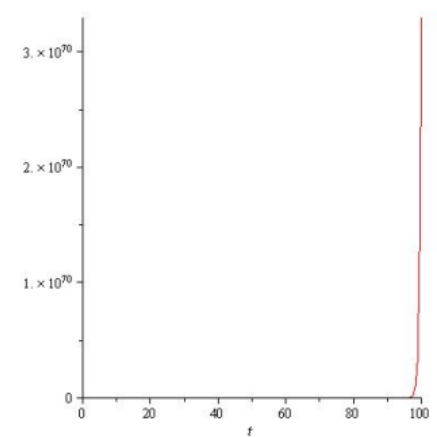

Gambar 4. Grafik $I(t)$ untuk $t \rightarrow 100$

Berdasarkan Gambar 4, diperoleh bahwa tingkat persediaan $I(t)$ mengalami kenaikan pada waktut $\rightarrow 100$. Persediaan barang terus mengalami kenaikan yang dimulai sejak $t=16$ sampai $t=100$.Hal ini disebabkan karena meskipun terdapat permintaan dan kerusakan yang terjadi pada barang, produksi tetap dilakukan sehingga menyebabkan tingkat persediaan barang terus mengalami kenaikan.Artinya, perusahaan harus mengurangi jumlah produksi untuk menstabilkan tingkat persediaan. Sehingga dapat diambil kesimpulan bahwa tingkat persediaan $I(t)$ tidak stabil untuk waktu $t \rightarrow 100$

\section{Kesimpulan}

Berdasarkan uraian pada pembahasan yang telah diberikan, diperoleh persamaan tingkat persediaan sebagai berikut:

a. Untuk fungsi $W_{b}$ adalah konstan

Persamaan tingkat persediaan yaitu

$$
I(t)=c_{1} e^{r_{1} t}+c_{2} e^{r_{2} t}+Q(t)
$$

Dengan

$$
r_{1}=\sqrt{\left(\frac{h}{K}+\left(W_{b}\right)^{2}\right)}=r \quad r_{2}=-\sqrt{\left(\frac{h}{K}+\left(W_{b}\right)^{2}\right)}=-r
$$

dan

$$
Q(t)=\frac{\frac{h}{K}+W_{b}\left(a-b-c t^{2}+P-2 \hat{P}+\frac{\lambda}{K}\right)+b+2 t}{\left(\frac{h}{K}+W_{b}^{2}\right)}
$$

b. Untuk fungsi $\frac{h}{K}+\left(\frac{d}{d t} W_{b}\right)+\left(W_{b}\right)^{2}$ adalah konstan

Persamaan tingkat persediaan yaitu

$$
I(t)=\left(c_{1}+W_{b 1}\right) e^{k_{1} t}+\left(c_{2}+W_{b 2}\right) e^{-k_{2} t}+\frac{h}{K k_{1}^{2}} \hat{I}
$$




\section{Daftar Pustaka}

[1] Affandi, Pardi, Faisal, dan Y. Yulida. 2015. Kendali Optimal dari Sistem Inventori dengan Peningkatan dan Penurunan Barang.Jurnal MIPA UNLAM,38 (1), (2015). 79-88.

[2] Azizah, Nur. Analisis Model EOQ dengan Adanya Kerusakan Barang pada Persediaan dan Perubahan Tingkat Permintaan.Jurnal Matriks,1(1), 2018.

[3] Begum, R. An EOQ Model for Deteriorating Items with Weibull Distribution Deterioration, Unit Production Cost with Quadratic Demand and Shortages. Applied Mathematical Sciences, 4(6), 2010. 271 - 288.

[4] Hazmuzalipa. Kendali Optimal pada Model Persediaan Barang yang Mengalami Weibull Deterioration pada Waktu Berhingg, Skripsi, Jurusan Matematika, Universitas Islam Negeri Sultan Syarif Kasim Riau, Pekanbaru, 2018.

[5] Johannes, Prof. H. dan Budiono Sri Handoko. Pengantar Matematika untuk Ekonomi, LP3ES, Jakarta, 1994.

[6] Lewis, F. L. Optimal Control. John Wiley \& Sons, Inc, Toronto, 1995.

[7] Pulungan, Dian Serena dan Erika Fatma. Analisis Pengendalian Persediaan Menggunakan Metode Probabilistaik dengan Kebijakan Backorder dan Lost Sales.Jurnal Teknik Industri, 19(1), 2018.34-38.

[8] Olsder, GJ. Mathematical System Theory.University of Technology, Delft, 1994.

[9] Ross, Shepley L. Differential Equations, Third Edition.University of New Hampshire, New York, 1984.

[10] Sethi, Suresh P, dan Thomson, Gerald L., Optimal Control Theory, Springer, New York, 2006

[11] Sharma, Vikas, dkk. An Inventory Model for Deteriorating Items with Weibull Deterioration with Time Dependent Demand and Shortages.Research Jurnal of Management Sciences,2(3), 2013.1-4.

[12] Tajd, Lotfi, dkk. Optimal Control of an Inventory System with Ameliorating and Deteriorating Items.Applied Sciences, 10, 2008.243-255.

[13] Wahyu, Widodo Kurniawan. "Pengembangan Sistem Informasi Persediaan Barang Terdistribusi (Studi Kasus:PT Master Centranusa Cemerlang)". Skripsi: Universitas Islam Negeri Syarif Hidayatullah, Jakarta. 2009.

[14] Walpole, Ronald E, dan Myers, Raymond H. Ilmu Peluang dan Statistik untuk Insinyur dan Ilmuwan. ITB, Bandung, 1995.

[15] Xie, Wei-Chau.Differential Equations for Engineers.University of Waterloo Cambridge, New York, 2010. 